\title{
Bioleaching of Chalcopyrite-bornite and Chalcopyrite-pyrite Mixed Ores in The Presence of Moderately Thermophilic Microorganisms
}

\author{
Yulin Huang ${ }^{1,2}$, Yisheng Zhang ${ }^{1,2}$, Hongbo Zhao ${ }^{1,2 *}$, Yanjun Zhang ${ }^{1,2}$, Yuming Xiong ${ }^{1,2}$, \\ Luyuan Zhang ', , Jun Zhou ${ }^{1,2}$, Jun Wang ${ }^{1,2}$, Wenqing Qin ${ }^{1,2}$, Guanzhou Qiu ${ }^{1,2}$ \\ ${ }^{1}$ School of Minerals Processing \& Bioengineering, Central South University, Changsha 410083, \\ Hunan, China \\ ${ }^{2}$ Key Lab of Bio-hydrometallurgy of Ministry of Education, Changsha 410083, Hunan, PR China \\ *E-mail: zhbalexander@csu.edu.cn; $\underline{\text { alexandercsu@126.com }}$
}

doi: $10.20964 / 2017.11 .33$

Received: 21 July 2017 / Accepted: 11 September 2017 / Published: 12 October 2017

\begin{abstract}
In this work, bioleaching of chalcopyrite-pyrite and chalcopyrite-bornite mixed ores in the presence of moderately thermophilic microorganisms (A.caldus, L.ferriphilum and mixed culture) were carried out. Bioleaching results showed that bioleaching behaviors of chalcopyrite-pyrite and chalcopyrite-bornite mixed ores in the presence of these moderately thermophilic microorganisms were all in accordance with the proposed optimum redox potential theory. Results showed that high copper extraction was obtained in different bioleaching systems if the redox potential was between $\mathrm{E}_{\mathrm{L}}$ to $\mathrm{E}_{\mathrm{H}}$. Real-time PCR technique was used to analyze the change of percentages of A.caldus and L.ferriphilum during bioleaching by mixed culture consisting of A.caldus and L.ferriphilum. Results showed that the change rules were similar between bioleaching system of sole chalcopyrite and two kinds mixed ores, indicating that the chemical factor instead of biological factor should be the main cause for the high copper extraction of chalcopyrite-pyrite and chalcopyrite-bornite mixed ores.
\end{abstract}

Keywords: Chalcopyrite; Pyrite; Bornite; Redox potential; Real-time PCR

\section{$\underline{\text { FULL TEXT }}$}

(C) 2017 The Authors. Published by ESG (www.electrochemsci.org). This article is an open access article distributed under the terms and conditions of the Creative Commons Attribution license (http://creativecommons.org/licenses/by/4.0/). 